Hexal, Sanofi, and USB; advisory board: AbbVie, Bio Skin, Bristol-Myers Squibb, Celgene, Dignity, Eli Lilly, Galapagos, GlaxoSmithKline, Janssen Cilag, Leo Pharma, Morphosis, Novartis, Pfizer, Sandoz, Sanofi, and UCB, Nicola Booth Employee of: Adelphi Real World, Steve Lobosco Employee of: Adelphi Real World, Gary Milligan Employee of: Adelphi Real World, Matthew Hufford Shareholder of: Eli Lilly and Company, Employee of: Eli Lilly and Company, Julie Birt Shareholder of: Eli Lilly and Company, Employee of: Eli Lilly and Company, Wolf-Henning Boehncke Consultant for: Pfizer Inc, Speakers bureau: Pfizer Inc, Elizabeth Holdsworth Employee of: Adelphi Real World DOI: 10.1136/annrheumdis-2019-eular.1919

\section{AB0784 SUBCLINICAL MYOCARDIAL INVOLVEMENT IN PSORIATIC ARTHRITIS PATIENTS}

${ }^{1}$ Nikolaos Tsigaridas", Stavros Mantzoukis ${ }^{1}$, Eleni Toli ${ }^{1}$, Konstantinos Tsimos ${ }^{1}$, Nikolaos Varsamis ${ }^{1}$, Maria Gianniki ${ }^{2}$, Marina Gerasimou' ${ }^{1}$, Dimitrios Patsouras ${ }^{1}$, Niki Tsifetaki'. . 'General Hospital of loannina "G. Hatzikosta", loannina, Greece; 2"Aghia Sophia" Children's Hospital, Athens, Athens, Greece

Background: Psoriatic arthritis (PsA) is a systemic inflammatory disease affecting $15-30 \%$ of patients with psoriasis ${ }^{1}$. Patients with PsA present $43 \%$ higher risk of cardiovascular disease, involving myocardial infarction, heart failure and cerebrovascular events compared with the general population $^{2}$. The common underlying pathophysiologic basis of these clinical events is early atherosclerosis. Myocardial fibrosis in the context of systemic inflammation ${ }^{3}$ seems to play a significant role in the cardiac manifestations of the disease as well. However, only a few trials have evaluated the possibility of recognition of myocardial involvement in its subclinical phase, which might be of value in reducing the morbidity and mortality of the disease.

Objectives: Our goal was to evaluate the systolic and diastolic myocardial function in asymptomatic patients with PsA and no cardiac comorbidities and emphasize the value of speckle tracking echocardiography in this condition.

Methods: Sixty patients (29 males) and 34 healthy controls (18 males) participated in the study. The patients' mean age was $52.5(\mathrm{~s} . \mathrm{d}=11.29)$ and the controls' mean age was 50.7 years $($ s.d. $=17.42$ ). They were all subjected to 2D transthoracic echocardiography, tissue Doppler imaging, and speckle tracking echocardiography, in order to evaluate left ventricular systolic function with conventional indices such as ejection fraction $(E F)$, and with novel indices such as global longitudinal strain (GLS). Diastolic dysfunction was also assessed in both groups. Blood tests including CRP and ESR were conducted. Disease duration and severity scores, PASI and DAS 28, were also recorded. The statistical analysis was conducted with SPSS v.23.0.

Results: Linear regression analysis showed statistically significantly impaired left ventricular systolic function $(p<0,001)$, as assessed with global longitudinal strain (GLS), in PsA patients (mean $=-19.79$, s.d. $=4.54$ ) compared to the controls (mean $=-23.67$, s.d. $=3.27$ ). The results were adjusted for age and gender. Ejection fraction, on the contrary, did not show any statistically significant difference between the two groups $(p=0,535)$. Left ventricular diastolic function did not present significant difference between the two groups. GLS showed no association with disease duration, severity scores or the blood tests.

Conclusion: PsA patients present a higher risk of left ventricular systolic dysfunction compared to controls. GLS measured by speckle tracking echocardiography is a useful tool in revealing this subclinical myocardial impairment.

\section{REFERENCES}

[1] Gladman DD, Antoni C, Mease P, Clegg DO, Nash P. Psoriatic arthritis: epidemiology, clinical features, course, and outcome. Ann Rheum Dis 2005;64 Suppl 2:ii14-7

[2] Polachek A, Touma Z, Anderson M, Eder L. Risk of Cardiovascular Morbidity in Patients With Psoriatic Arthritis: A Meta-Analysis of Observational Studies. Arthritis Care \& Research Vol. 69, No. 1, January 2017, pp 67-74

[3] Kania G, Blyszczuk P, Eriksson U. Mechanisms of cardiac fibrosis in inflammatory heart disease. Trends Cardiovasc Med 2009; 19: 247-252

Disclosure of Interests: None declared DOI: 10.1136/annrheumdis-2019-eular.6193

\section{$\mathrm{AB} 0785$} DRUG SURVIVAL OF SECUKINUMAB FOR PSORIATIC ARTHRITIS IN A REAL-WORLD SETTING

${ }^{1}$ Marta Valero", Beatriz Joven-Ibáñez ${ }^{2}$, María Martín², Jose Campos Esteban ${ }^{3}$, Carolina Merino Argumánez ${ }^{3}$, Valentina Emperiale ${ }^{4}$, Ana Pérez Gómez ${ }^{4}$, Javier Bachiller-Corral ${ }^{1} .{ }^{1} H U$ Ramón y Cajal, Madrid, Spain; ${ }^{2} H U 12$ de Octubre, Madrid, Spain; ${ }^{3} \mathrm{HU}$ Puerta de Hierro, Majadahonda, Spain; ${ }^{4} \mathrm{HU}$ Príncipe de Asturias, Alcalá de Henares, Spain

Background: Secukinumab is a newly introduced biologic therapy against IL-17 which has been approved for Psoriatic Arthritis and has showed efficacy in clinical trials, but real world data is still lacking.

Objectives: This study aims to analize secukinumab drug survival for psoriatic arthritis in a real world environment.

Methods: Multicentric observational, longitudinal retrospective study conducted at 4 tertiary hospitals in Madrid region. Patients with clinical diagnosis of psoriatic arthritis which had received at least one dose of secukinumab between january 2016 and october 2018 were included. with follow up period till December 31, 2018. Medical records were reviewed to collect data about psoriatic arthritis involvement, comorbidities, previos DMARD and bDMARD therapies and its reasons for discontinuation, duration of secukinumab therapy, reasons for discontinuating secukinumab therapy and adverse events. Statistical analysis was performed including bivariate analisys (considering withdrawal of drug during study period or not) and survival analysis with Kaplan-Meier and Cox regression.

Results: 177 patients that initiated secukinumab therapy in the recruitment period were included. 123 pacients were on $150 \mathrm{mg}$ dose and 54 on $300 \mathrm{mg}$ dose. Average follow up period was 13 months (SD 8,28; range 1-34) In the bivariate analysis, a higher proportion of biologic-naïve patients was found among the group without secukinumab withdrawal during the study $(40 \%$ vs $23 \%$, p 0.07). No other differences were observed between both groups regarding demographic characteristics nor comorbidities (tobacco exposure, hypertension, diabetes mellitus, dyslipidemia ischemic heart disease or malignancy). Median survival time for secukinumab in the Kaplan-Meier analysis was 21.2 months (IC 95\%: 14.3 22.2), with an average of 19,9 months. One event was censored due to lost to follow-up. Secukinumab treatment was withdrawn in 79 patients $(44.6 \%)$. Reasons for discontinuation were lack of effectiveness $(37 \%)$, either primary (40 patients) or secondary (26 patients), adverse events ( 9 patients, $0,5 \%$ ), elective surgery in one patient and latex allergy in other The only variable associated to higher drug survival in Cox regression analysis was biologic-naïve status. No differences in drug survival were found in all other variables studied (gender, age, secukinumab dosage, illness duration, clinical features, tobacco exposure and rest of comorbidities).

Conclusion: As secukinumab was marketed in 2016, real-word setting studies lack long term data. The mean follow up period in our study was 13 months. Most of withdrawals were to lack of effectiveness. Median survival was 21.2 months, significatively higher in biologic-naïve patients. No other differences were found in all other variables studied. Probably real-world data differ from those of clinical trials.

Disclosure of Interests: Marta Valero: None declared, Beatriz Joven-lbáñez Speakers bureau: Celgene, Novartis, MSD, Pfizer, AbbVie, and Jans sen, María Martín: None declared, Jose Campos Esteban: None declared, Carolina Merino Argumánez: None declared, Valentina Emperiale: None declared, Ana Pérez Gómez: None declared, Javier Bachiller-Corral: None declared

DOI: 10.1136/annrheumdis-2019-eular.395

\section{AB0786 HIGH TREATMENT SATISFACTION OF THERAPY WITH USTEKINUMAB IN PATIENTS WITH ACTIVE PSORIATIC ARTHRITIS DUE TO EARLY AND LONG-TERM TREATMENT RESPONSE AND HIGH TOLERABILITY - RESULTS OF THE NON-INTERVENTIONAL STUDY SUSTAIN}

${ }^{1}$ Joerg Wendler", Peter Wagener², Frank Hamann ${ }^{3}$, Nils Damann ${ }^{4}$, Evgenia Movshovich ${ }^{4}$, Frank Behrens ${ }^{5} .{ }^{1}$ Rheumatologische Schwerpunktpraxis, Erlangen, Germany, ${ }^{2}$ Fachpraxis für Rheumatologie und Osteologie, BruchhausenVilsen, Germany; ${ }^{3}$ Gemeinschaftspraxis für internistische Rheumatologie, Leipzig, Germany; ${ }^{4}$ Janssen-Cilag, Neuss, Germany; ${ }^{5}$ Rheumatologie and Fraunhofer Institut IME -TMP, Frankfurt, Germany 
Background: SUSTAIN is a prospective, multi-center non-interventional study in Germany.

Objectives: The objectives are to observe long term efficacy and safety, quality of life and further patient reported outcomes in patients with active psoriatic arthritis (PsA) under treatment with ustekinumab in routine clinical care.

Methods: In this study nearly 400 patients were planned to be included at 75 centers for 160 weeks with documentation intervals at week 0 and 4 and then every 12 weeks. The treatment with ustekinumab is according to the label. Besides demographic data, the following data will be documented: Number of swollen and tender joints, tender entheses, amount of skin psoriasis (BSA and PASI), patient reported outcome concerning disease activity of PsA and pain, Health Assessment Questionnaire (HAQ), quality of life (SF-12), sleep quality (VAS), satisfaction with therapy of patient and physician, safety (adverse events/serious adverse events), pharmacoeconomic aspects, number of patients with "Minimal Disease Activity" (MDA), number of patients with MDA at week 28 und 52. For the present interim analysis baseline data of 336 patients and results of the documented visits up to week 112 were analyzed.

Results: For the present analysis 336 patients (57\% women) at 75 centers were observed. The number of documented patients was 310 at week 4,318 at week 16, 278 at week 28, 160 at week 76 and 108 at week 112. At time of inclusion into the study, patients had arthritis at small $(73.2 \%)$ and/or large $(52.4 \%)$ joints, spinal involvement $(17 \%)$ and enthesitis $(13.1 \%)$. For $30.1 \%$ of patients, the medical history revealed structural bone damage and $2.1 \%$ had uveitis present at time of inclusion. Mean age was 54 years (22-85), mean BMI $30 \mathrm{~kg} / \mathrm{m}^{2}$ (19-52). The mean ustekinumab dose was $0.7 \mathrm{mg} / \mathrm{kg}$ body weight $(0.2-1.3)$. $54.5 \%$ of the patients had as prior medication at least one TNF inhibitor and $44 \%$ used MTX as concomitant medication.

The data extension of the present interim analysis demonstrated relevant improvements with high treatment satisfaction and good safety and tolerability after 4 weeks and up to 112 weeks. The data show the maintenance of these treatment results up to week 112 , i.e. reduction in the number of tender joints from a mean of $10.0(\mathrm{Cl} 95 \% 8.6 / 11.3)$ at baseline to $1.8(1.1 / 2.5)$ at week 112 . The number of swollen joints improved from $4.1(3.4 / 4.9)$ at baseline to $0.7(0.3 / 1.0)$ at week 112. In the same period, skin symptoms (PASI) declined from 8.4 to 1.0 and pain assessment (VAS) declined from 56.0 to 34.3. Of the 96 patients who completed the week 112, 30.2\% reached MDA at week 28 and $29.2 \%$ reached MDA at week 52

Efficacy of the therapy with ustekinumab was assessed as "very good" or "good" by $91.1 \%$ of the treating physicians and by $89.9 \%$ of the patients at week 112. Until data cut off point (45 months after study start), 105 SAEs have been documented, of which only 14 were related to ustekinumab as assessed by physician of treatment center. $3.9 \%$ of patients discontinued treatment with ustekinumab $(\mathrm{N}=121)$, mainly due to an adverse event. Safety of therapy with ustekinumab was assessed as "very good" or "good" by $100 \%$ of the treating physicians and by $100 \%$ of the patients at week 112 .

Conclusion: The present interim analysis of the prospective non-interventional study SUSTAIN confirmed relevant improvements with high treatment satisfaction and good safety in patients with active psoriatic arthritis treated with ustekinumab after 4 weeks and demonstrated that these effects were maintained at least up to 112 weeks in routine care.

Disclosure of Interests: Joerg Wendler Consultant for: Roche Pharma AG, AbbVie, Jannssen Cilag, Novartis, Speakers bureau: Roche Pharma AG, AbbVie, Jannssen Cilag, Novartis, Peter Wagener: None declared, Frank Hamann: None declared, Nils Damann: None declared, Evgenia Movshovich: None declared, Frank Behrens Grant/research support from: AbbVie, Pfizer, Roche, Chugai, Prophylix, Bioline, Novartis, Consultant for: AbbVie, Pfizer, Roche, Chugai, UCB, Bristol-Myers Squibb, Celgene, MSD, Novartis, Biotest, Janssen, Genzyme, Eli Lilly, Speakers bureau: Ad board: AbbVie, Pfizer, Roche, Chugai, UCB, Bristol-Myers Squibb, Celgene, Novartis, Biotest, Janssen, Genzyme, Eli Lilly

DOI: 10.1136/annrheumdis-2019-eular.4655

\section{$\mathrm{AB} 0787$}

TREATMENT TRENDS IN PSORIATIC ARTHRITIS IN A REAL-WORLD SETTING; RESULTS FROM A HEALTH PROVIDER DATABASE OF THE PSORIATIC ARTHRITIS PATIENTS

Amir Haddad ${ }^{1}$, Faten Tatour ${ }^{1}$, Tal Gazitt', Ilan Feldhamer ${ }^{2}$, Irina Bergman ${ }^{1,3}$ Arnon Cohen ${ }^{4},{ }^{1,3}$ Devy Zisman ${ }^{*} .{ }^{1}$ Carmel Medical Center, חיפ, Israel; ${ }^{2}$ Clalit Health Services, Tel Aviv-Yafo, Israel; ${ }^{3}$ The Ruth and Bruce Rappaport Faculty of Medicine, Haifa, Israel; ${ }^{4}$ Ben Gurion University of the Negev, באר שבע, Israel

Background: Emerging Psoriatic Arthritis (PsA) treatments have had a great impact on treatment strategies and healthcare costs in PsA disease management. Therefore, investigating changes in therapy is important to patients, healthcare providers, and healthcare payers alike.

Objectives: To describe changes in treatment strategies and management of PsA patients in a real-world setting over the years 2000-2017 since the introduction of diverse novel biologic disease modifying anti-rheumatic drugs (bDMARDS).

Methods: A retrospective study was performed using the previously-tested and validated database of Clalit Health Services, the database of the largest healthcare provider in Israel. The database includes continuous real-time input from pharmaceutical and medical digital systems regarding prescribed and dispensed medications. In this study, data on all conventional DMARDs (cDMARDs) and bDMARDs dispensed to the PsA patient cohort from 2000-2017 was retrieved. In Israel, all patients are eligible for bDMARDS following treatment failure of at least 2 cDMARDS with bDMARDs used in different sequences and/or combinations based on patient and physician preference. Of note, Etanercept and Infliximab are available on the Israeli market since 2000, Adalimumab since 2002, Golimumab since 2006 and Ustekinumab since 2014. Descriptive statistics, including means (standard deviations) for continuous variables and frequencies (\%) for categorical variables, were used.
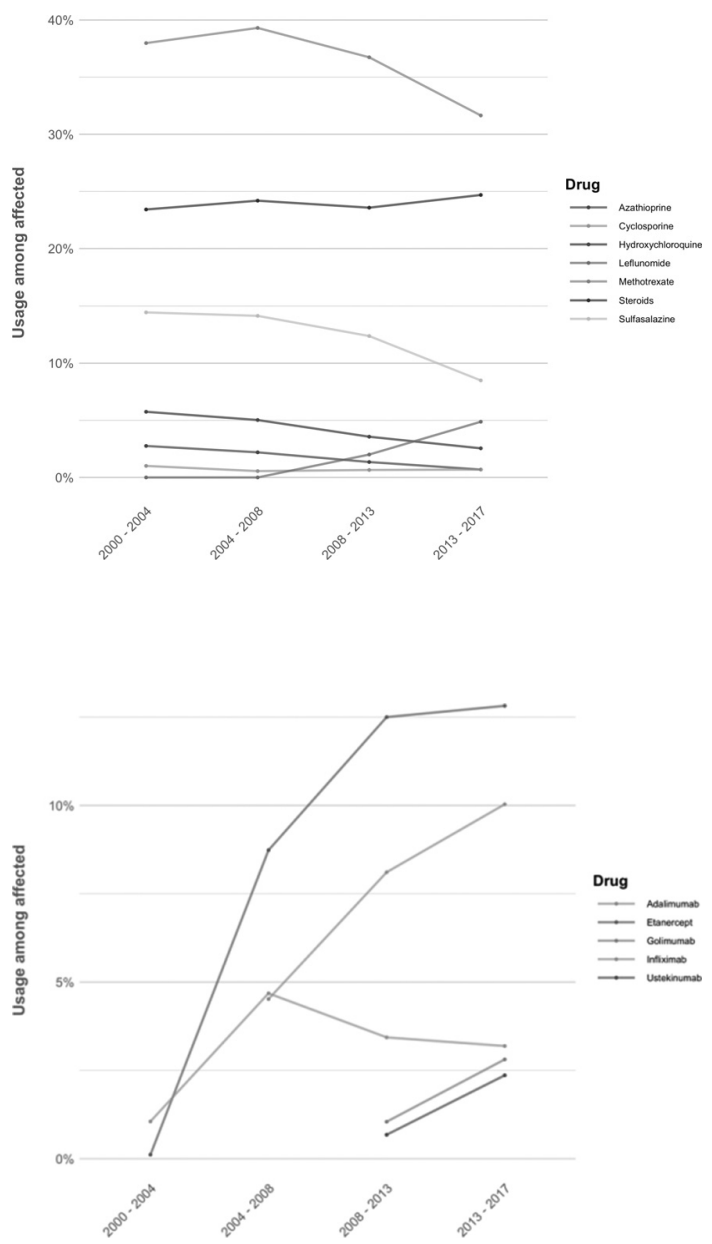